\title{
CBC - Fórum de Pesquisa em Cirurgia - 25 anos
}

\section{$C B C$ - Workshop on surgery research - 25 years}

ECBC - RJ - Orlando Marques Vieira

Ex-Presidente do Colégio Brasileiro de Cirurgiões

Nosion dia 10 de novembro de 2010 foi realizado o XXV Fórum de Pesquisa do Colégio Brasileiro de Cirurgiões, organizado pelo Núcleo Central.

O Jubileu de Prata deste evento revestiu-se da maior importância, pois demonstrou a participação ativa do $C B C$, no desenvolvimento da cirurgia e principalmente na divulgação da pesquisa cirúrgica.

A idéia do Fórum foi lançada em 1986, quando era Presidente o ECBC Guilherme Eurico e nós Vice-Presidente do Núcleo Central.

O objetivo era o de proporcionar aos nossos cirurgiões, pesquisadores e observadores a divulgação dos seus achados e progressos, principalmente na técnica e na ciência cirúrgica.

Os Congressos e reuniões reservavam pequenos espaços à pesquisa experimental, talvez por esta atividade não provocar, na época, uma demanda importante nestes eventos. Deste modo resolvemos investir neste tipo de reunião, voltada unicamente para os trabalhos experimentais.

Os cirurgiões sempre se apoiaram em observações, achados e demonstrações de laboratórios ou de experimentações, no princípio incipientes, mas marcantes para o crescimento futuro.

Podemos verificar que com os estudos de Anatomia e a obra completa de Andreas Vesalius (1514-1564) os cirurgiões compreenderam que era preciso conhecer anatomia para exercer a cirurgia.

Com o conhecimento básico de Vesalius, Ambroise Paré (1510-1590) trouxe observações importantes e mudou a prática cirúrgica e é considerado o pai da cirurgia moderna. Praticou a ligadura dos vasos para hemostasia.

William Harvey (1578-1657) em sua obra sobre a circulação sanguínea, afirmou que esta estava contida em um único sistema e era contínua, sem dúvida foi a maior observação do século XVII. Foi considerada a obra mais importante da História da Fisiologia.

A grande revolução da experimentação foi causada por Claude Bernard (1813-1878), que é lembrado como o fundador da fisiologia experimental com seu magnífico trabalho: "Introdução ao Estudo da Medicina Experimental" editado em 1865

Alexis Carrel (1873-1944) foi um extraordinário pesquisador e desenvolveu a técnica de anastomoses dos vasos, o que facilitou um amplo progresso na cirurgia. Por seus trabalhos ganhou o Prêmio Nobel de Medicina em 1912.
Posteriormente, já no início para a metade do século XX foram instaladas as cirurgias experimentais, e estas se incorporaram ao aperfeiçoamento de técnicas e a investigação dos princípios cirúrgicos, mas ainda não agregadas aos serviços de cirurgia.

O grande avanço da cirurgia experimental se deu com a associação da experimentação a prática cirúrgica. Neste momento e com grande propriedade os procedimentos passavam pela experimentação. Surgiram a circulação extracorpórea em 1953 com Walton Lillehei (1918-1999). A seguir os transplantes de rim em 1954 com Joseph Murray, o transplante de fígado com Thomas Starzl em 1964 e Christian Barnard com o transplante cardíaco em 1967. Devemos citar ainda a vídeo cirurgia, também, muito ligada e desenvolvida pela experimentação.

A cirurgia sempre estará aliada ao progresso científico e a experimentação proporcionou este desenvolvimento.

Precisávamos, portanto, incentivar e divulgar os nossos avanços e projetos, daí a ideia do Fórum de Pesquisa iniciado em 1968 partiu da premissa de que o CBC abrigaria o Fórum e dedicaria um dia do ano a ele, não seriam cobradas inscrições, estas se formalizariam com a apresentação dos trabalhos, somente, de cirurgia experimental. O Fórum de Pesquisa em Cirurgia do CBC é regimental e criou-se a obrigação de realizá-lo.

Em 25 anos foram apresentados cerca de 1400 trabalhos. Foram criados os prêmios, Alfredo Monteiro, para o melhor trabalho do Fórum, Ruy Ferreira Santos para o trabalho com melhor aplicabilidade clínica e o Mariano de Andrade para a Instituição que apresentar o maior número de trabalhos com qualidade.

Já realizamos o Fórum por 25 anos ininterruptos. Esperamos que seja uma conquista definitiva, pois acreditamos que os apresentadores tem valorizado o evento e encontram oportunidade para divulgação.

A sessão solene do Jubileu de Prata do Fórum foi incentivada pelo Presidente do CBC - TCBC Gaspar de Jesus Lopes e pelo vice Presidente do Núcleo Central - TCBC Fernando Cesar David. Certamente o maior êxito do evento foi obtido pelos participantes que valorizaram com seus trabalhos uma iniciativa importante.

Nesta sessão foram homenageadas as Instituições que mais contribuíram para o Fórum nos 25 anos de 
existência. As Instituições homenageadas foram a UNIFESP (Universidade Federal de São Paulo); a UFMG (Universidade Federal de Minas Gerais); a UFRN (Universidade Fede- ral do Rio Grande do Norte); Hospital e Maternidade Angelina Caron do Paraná e a UFRJ (Universidade Federal do Rio de Janeiro). 